\title{
Flipped Classroom Teaching Research on the Excellent Resource-sharing Course of Computer Aided Clothing Drawing
}

\author{
Ru-Nan JIANG \\ School of Art and Design, Wuyi University, Jiangmen, Guangdong, 529020, China \\ 18227843@qq.com
}

Keywords: Flipped classroom, computer aided clothing drawing, teaching model.

\begin{abstract}
The flipped classroom teaching model is applied in excellent resource-sharing course of computer aided clothing drawing. The well-designed teaching videos and skillful settings of post situation not only can improve quality of online learning, but also can promote effects of knowledge internalization through collaboration and interaction and student-student comments.
\end{abstract}

\section{Introduction}

The so-called flipped classroom is a new-type teaching model that under the information environment, a course teacher provides learning resources with the major form of teaching videos, students view and learn teaching videos before the class, and then the teacher and students finish tasks, answer questions, collaborate and explore, interact and communicate with each other in the class $^{[1]}$. In terms of the excellent resource-sharing course of computer aided clothing drawing, how to explore the typical features, theoretical foundation and practical main ideas of flipped classroom and form strategies and methods of course teaching reform and innovation, as well as how to take full advantage of flipped classroom model to promote course teaching quality and cultivate students' ability and quality should be urgently solved by every course teacher.

\section{The Connotation of Flipped Classroom Teaching Model}

The teaching process of traditional classroom should "teach before learning". Besides compulsive infusion of teaching contents, it also limits students' in-class reflection, questions and discussions from time. Thus, the teaching effects may not be ideal. On the contrary, the flipped classroom applies the form that combines "pre-class teaching" with "in-class internalization". The teaching process is to "learn before teaching". Before the class, students learn the online education videos established by teachers autonomously. Then, the classroom is transformed into a place for asking and answering questions, cooperative learning and knowledge internalization. The flipped classroom is the product of greatly reforming the classroom teaching model. Under the guidance of mixed learning theory, the face-to-face teaching is combined with the online teaching and this is a brand-new learning model. The flipped classroom extremely conforms to the cognitive rules of students. The teacher explanation is replaced by video teaching, thus the guiding function of teachers can help students in trouble or in confusion. The flipped classroom is the result of deeply integrating information technology with classroom teaching. It can deal with the complicated relation among teachers, students and courses systematically, observe and regulate teaching process in real time. On the other hand, teachers can carry out teaching by aiming at specific situations reflected by data statistics.

\section{Feasibility Analysis of Applying the Flipped Classroom Teaching Model in the Excellent Resource-sharing Course of Computer Aided Clothing Drawing}

The excellent resource-sharing course of computer aided clothing drawing is the core basic course in fashion design major. The target of the course aims at cultivating students' basic ability to apply Coreldraw, Illustrator and Photoshop to draw illustration of different types of garments, so as to lay a solid foundation on learning subsequent professional courses. The course integrates with software 
operation, artistic aesthetics and painting skills effectively. With teaching and training in techniques of expression, such as styles, colors, modeling, texture and pattern of costumes, it enables students to possess the computer drawing ability to express design intention accurately.

From the perspective of applying the flipped classroom teaching model, on the one hand, the excellent resource-sharing course of computer aided clothing drawing gives priority to practical training of computer drawing. It has open and flexible contents and is suitable for autonomic learning, cooperative learning and explosive learning based on online videos before the class, as well as asking-answering model and interactive practice based on teacher-student collaboration in the class. On the other hand, the refresh rate of mapping software version also proposes the higher requirement for students' autonomous learning and knowledge transfer ability. As a result, only to unify web-based learning and classroom teaching organically can it satisfy the training demands for students' learning ability. In addition, the internet environment in colleges is relatively perfect. They generally apply the online teaching platform and have mature conditions to carry out personalized teaching services. Students' information ability and fashion attainment in costume designing are relatively strong. The owning rate of PC, laptop and smartphone is almost $100 \%$. Students in this major are proficient in mastering basic applications of computers and operational skills of social contact software and have conditions of autonomic learning. As a result, the application of the flipped classroom teaching model in the excellent resource-sharing course of computer aided clothing drawing not only promotes the sufficient application of school resources and conforms to the course development demands under the strong requirements of practice, but also can satisfy practical demands for students' knowledge seeking, and thus it is totally feasible.

\section{The Teaching Measures of the Excellent Resource-sharing Course of Computer Aided Clothing Drawing Based on the Flipped Classroom Teaching model}

In the excellent resource-sharing course of computer aided clothing drawing, it should set up the standard concept of students, reform the traditional thought of "being teacher-centered", and return to the educational essence of "being student-centered". The teaching should be carried out from multiple aspects of the course and the specific measures are shown as follows:

\section{A. To compile course contents based on teaching videos}

No matter it is the Khan Academy with "re-education with videos" or MOOC of "taking down constraints of colleges", both of them apply the flipped classroom teaching model skillfully and it is extremely worthy of study and reference. In the design of course contents, the traditional classroom requires for completeness and systematicness of knowledge, while flipped classroom applies the debris process model to subdivide course contents into the minimal knowledge element. It has the way of presentation for micro-video within 20min. It will implant some exercise or tests in micro-video and use customs pass of similar games to promote and supervise learning. The flipped classroom also applies the design method with the priority of core knowledge. The course is connected with the isolated micro-video, lays off a learning line for learners and guides learners to go deep gradually. Thus, it can be observed that a teaching video is the foundation to implement the flipped classroom teaching. The modular resolution and debris processing of course contents are the key to compile online teaching contents.

The teaching features in the excellent resource-sharing course of computer aided clothing drawing mean that teachers integrate theoretical knowledge of garments with operating points of mapping software to form main ideas of computer drawing and apply practical operation of computers. On the other hand, students watch and memorize it, comprehend and master in repeated exercises, so as to form the basic computer drawing skills. Teachers can firstly use video recording software to record teaching voice, images and the entire operation process and use multi-media authoring software to do post-production to form a teaching video. The format and capacity of every teaching video should be good for students to browse online or save by downloading. The utilization way of videos should be humanized. Students can some functions, such as forward, backward, pause and play, and customize their learning rhythm. The duration of a video generally is about $10 \mathrm{~min}$. It is necessary to ensure that students' attention can be kept in the best state. Video 
contents should stand out key points and difficult points. It must simplify a key knowledge point or operational skill, so as to reduce cognitive loads of students and improve learning efficiency. Videos should stand out resource functions. This not only is used for preparing for self-study, but also can be used for making up missed lessons. For example, the teaching contents in the chapter of "garment material drawing" should be divided into three modules, including weaving material drawing, woven material drawing and needle material drawing. The module of weaving material drawing should conduct debris processing and record 9 short videos, including cross-grain jeans, corduroy, classical plover, Scottish plaid, completed blouse grids, herringbone, grey woolen cloth, hollow lace and special material drawing. Every short video should solve a main problem. By virtue of these short videos, students can learn it by themselves before the class, so as to master relevant knowledge points rapidly and completely, and conduct extensive learning.

\section{B. To carry out autonomic learning based on the job position}

As the biggest manufacturing base of clothing industry in the globe, China has speeded up the steps of upgrade industry in recent years. Digitalization and networking become the inexorable trend to develop the clothing industry. The software functions of computer drawing are powerful. Designers are liberated from the repeated labor of handwork drawing, so that they can modify, fill and render design drafts rapidly and repeatedly, so as to complete all kinds of design tasks effectively. For such a reason, the modern clothing enterprises have already widely applied computer drawing to design product research. Moreover, the computer design level of costumes is also an important index of assessing designers' post ability for modern clothing enterprises. One of essential core skills that must be possessed by enterprise designers should be proficient in computer drawing. For undergraduates in costume designing, above $90 \%$ of people will engage in design in enterprises. As a result, the excellent resource-sharing course of computer aided clothing drawing makes students complete plane style pictures and effect pictures of ready-made garments, drawing of lining, auxiliary materials, dress accessories and dress patterns according to design demands, so as to realize seamless joint with employment posts. On the other hand, it also should refer to skill standard structure of clothing designers to organize practical training and pay attention to cultivating artistic aesthetics and alternative transfer capability of applied skills for students, so as to improve applied level of computer drawing in clothing product realization.

In the flipped classroom teaching for the excellent resource-sharing course of computer aided clothing drawing, it should regard practical working of enterprise post as a teaching situation and apply a project teaching method to guide students to carry out automatic learning. For example, as drawing chapter contents of pattern, teachers should upload videos about computer drawing technology, including independent patterns, continuous patterns, complicated geometrical patterns and abstract patterns, etc., to the internet before one week of the class, ask students to watch them and use drawing software to learn relevant operating points by themselves. Meanwhile, the following tasks are proposed: The design director (a teacher) has a design project of men's ties with the theme of "Haiyun" and organizes a design team(30 students) to design 30 kinds of painted design. Every student should look up data by themselves, reflect it and use a computer to draw a design draft. In the class, the teacher has no need to teach basic knowledge points for specific pattern drawing methods, but should give the platform to students and let them display their computer design drafts one by one and give a presentation to all classmates for design process and ways of drawing. In this way, students can enlighten and complement mutually in the atmosphere of communication and competition. Students not only can finish the project, but also can design another two patterns in their spare time. Such a learning model not only is interesting and initiative for students, but also makes them have sense of autonomy and sense of achievements, thus it is deeply loved by students.

\section{To build the learning atmosphere by virtue of interaction and cooperation}

Learning atmosphere is the dynamic balance of various teaching factors in the classroom environment and is the existing and essential psychological environment in teaching activities. The essential condition for teachers and students' classroom communication and information transfer is to build the democratic, harmonious and loose learning atmosphere with ecological cooperation. 
Teaching process not only is a kind of cognition, but also is a kind of communication. The American psychologist Albert Bandura once pointed in his social learning theory that learning is conducted under the interaction of three elements, including environment, learners and cognitive behaviors ${ }^{[2]}$. The traditional classroom applies the single teacher-student interaction of teachers. The classroom atmosphere is precise and mechanical, but flipped classroom is the multi-dimensional interaction between teachers and students, students and teachers, students and students, individuals and groups, groups and individuals, individuals and individuals, as well as groups and groups. The classroom atmosphere is active and flexible. Only to realize interaction and cooperation between teachers and students can it realize the transformation from traditional classroom to flipped classroom thoroughly. Interaction and cooperation are obvious features of the flipped classroom teaching model and important safeguard of ordered teaching and high-efficient development. With the interaction and cooperation, teachers and students can share knowledge, experience and reflection, communicate emotion, experience and concept, reach a consensus, share and make progress together, and realize the idea that teaching benefits teachers as well as students. In the teaching environment of flipped classroom, students, teachers and partners can utilize the interactive course platform or SNS to realize extracurricular online communication, or utilize topic discussion, questions and answers, enlightenment and guidance to interact face to face.

The assignment of the excellent resource-sharing course of computer aided clothing drawing can be organized and implemented by virtue of interaction and cooperation in the whole class, groups, individuals and group cooperation. For example, an assignment requires for-simulating the spring-summer product development process in 2017. With the theme of "urban charm", the design of 300 new products in a quarter should be completed and presented in computer drawing. In the class, a teacher should firstly organize students to discuss. Everyone looks for design inspiration from urban impression and discusses the feasibility of extracting design elements from buildings, cultures, arts, folk customs and popularity. The teacher and students subdivide the theme into six sub-themes, including fashion party, artistic life, life wandering, afternoon sunshine, intelligent life, and colorful mixture. 30 students are divided into 6 groups. Every group should design a sub-theme. In addition, types of spring-summer products are relatively abundant. With the discussion, every sub-theme should arrange design schedule as early spring (woolen sweater, knitwear, short coat, jacket and underwear), early summer (skirt, pants and shirt), midsummer (T-shirt, vest and beachwear). After school, every group exchanges and communicates from various aspects, including design style position, category confirmation, single technology, lining selection, pattern color, and details of computer drawing, etc., face to face or SNS at anytime and anywhere. In this way, such a complicated design task is decomposed and every student have a chance to participate in it and can finish the course teaching task in positive, serious, high-quality and high-efficient interaction and cooperation.

\section{To create classroom comments with the means of student-student comments}

Classroom comments are important components in teaching. The educational functions run through every link of classroom activities. The single evaluation method of "being teacher-centered” in traditional classroom can't adapt to the current educational development. The student-student comments of "being student-centered" in flipped classroom are the powerful weapons to promote self-reflection and education of students, self-promotion and development. Students hope to be concerned and accepted by their partners for a little progress. This is a common psychology of students. Because learning level in partners is probably kept in the same level, the novel student-student comments and contents are easy to be accepted by valuators. In the process of evaluation and being evaluated, students can appreciate and encourage each other. This not only can settle their understanding and application on knowledge, but also can train and master exchange skills. The student-student comments not only contribute to constructing professional self-confidence and self-cognition for students, but also help to cultivate open mind and team awareness of students.

Based on the above-mentioned assignment in the excellent resource-sharing course of computer aided clothing drawing: after every group finishes a task, the important link is to carry out 
student-student comments and students in every group should have the uniform background of styles, design position, element extraction, category selection, style design, painting performance of every sub-theme to evaluate superiority and inferiority of the group design. For instance, whether the sub-theme of "artistic life"-design position of relaxed costumes is suitable. It should extract design elements from urban buildings and scrawl arts, abandon preciseness and rationality, use a destroy and irregular technique to break down the texture of regular patterns and picture surface of buildings, and stand out interesting design, whether such an artistic processing method is reasonable and whether categories, including skirt, pants and T-shirt, are comprehensive. Style design emphasizes on texture comparison, stresses on artistic features of patterns, and whether conforms to fashionable tendency. Computer drawing applies the grid lining texture, geometrical lining texture, painted character effects and abstract printed contents, etc., whether technical expression is correct. Finally, some specific suggestion on modification is proposed. Such the classroom evaluation form linking work at selected spots with that in entire areas not only intensifies technical points, expands design thinking, opens creative vision, promotes students to know about the entire product research process of clothing enterprises, and rapidly improves computer graphic ability, but also motivates students' thirst for knowledge, cultivates cooperative consciousness, reflective habits, analysis level and expressive ability, ensures that teachers concentrate on well-designed cooperative strategies, guides students' thinking development and concerns individual differences of students instantly.

\section{Summary}

Relative to the traditional classroom teaching model, the advantages of flipped classroom in teaching innovation are very obvious. It realizes the reverse reversal of classroom thinking and is the propellant of course reform in colleges. From the employment practice of students who major in costume designing, computer graphic ability has already become the essential basic professional skills of students in colleges and is the astepping-stone to success for college graduates. For the excellent resource-sharing course of computer aided clothing drawing under the flipped classroom teaching model, it should set up the idea of "being student-centered", take measures of "using teaching videos as the foundation on compiling course contents, using the post situation as the basis to carry out autonomic learning, using interaction and cooperation as a method to building learning atmosphere, and using the student-student comments as the means to create classroom evaluation, etc., so as to promote teaching effects and trigger major transformation of teaching view, resource view and classroom view of costume designing.

\section{Acknowledgments}

[Fund project] The paper is the achievement from the excellent resource-sharing course of computer aided clothing drawing in undergraduate quality project in Guangdong in 2014(Letter of Guangdong education[2014] No.97 and the "exploration and practice of mixed teaching model for costume designing based on the MOOC idea" in the teaching quality project in Wuyi University in 2015(JG2014028).

\section{References}

[1] Zhong Xiaoliu, Song Shuqiang and Jiao Lizhen, The Teaching Design Research in Information Environment Based on the Flipped Classroom, 2013(19),p. 60.

[2] Yang Jiaxing, Theoretical Foundation and Institutional Selection of Online Teaching [J], Chinese Distance Education, 2006(7),p. 16. 